\title{
Towards a uniform specification of light therapy devices for the treatment of affective disorders and use for non-image forming effects
}

Citation for published version (APA):

Aarts, M. P. J., \& Rosemann, A. L. P. (2018). Towards a uniform specification of light therapy devices for the treatment of affective disorders and use for non-image forming effects: radiant flux. Journal of Affective Disorders, 235, 142-149. https://doi.org/10.1016/j.jad.2018.04.020

Document license:

TAVERNE

DOI:

10.1016/j.jad.2018.04.020

Document status and date:

Published: 01/08/2018

Document Version:

Publisher's PDF, also known as Version of Record (includes final page, issue and volume numbers)

Please check the document version of this publication:

- A submitted manuscript is the version of the article upon submission and before peer-review. There can be important differences between the submitted version and the official published version of record. People interested in the research are advised to contact the author for the final version of the publication, or visit the $\mathrm{DOI}$ to the publisher's website.

- The final author version and the galley proof are versions of the publication after peer review.

- The final published version features the final layout of the paper including the volume, issue and page numbers.

Link to publication

\footnotetext{
General rights

- You may freely distribute the URL identifying the publication in the public portal. follow below link for the End User Agreement:

www.tue.nl/taverne

Take down policy

If you believe that this document breaches copyright please contact us at:

openaccess@tue.nl

providing details and we will investigate your claim.
}

Copyright and moral rights for the publications made accessible in the public portal are retained by the authors and/or other copyright owners and it is a condition of accessing publications that users recognise and abide by the legal requirements associated with these rights.

- Users may download and print one copy of any publication from the public portal for the purpose of private study or research.

- You may not further distribute the material or use it for any profit-making activity or commercial gain

If the publication is distributed under the terms of Article $25 \mathrm{fa}$ of the Dutch Copyright Act, indicated by the "Taverne" license above, please 
Research paper

\title{
Towards a uniform specification of light therapy devices for the treatment of affective disorders and use for non-image forming effects: Radiant flux
}

\author{
M.P.J. Aarts (Mariëlle)*, A.L.P. Rosemann (Alexander) \\ Chair Building Lighting, Unit Building Physics and Service, Eindhoven University of Technology, The Netherlands
}

\section{A R T I C L E I N F O}

\section{Keywords:}

Light therapy

Specification

Device

Non-image forming

Treatment

Affective disorders

\begin{abstract}
A B S T R A C T
Background: For treating affective disorders like SAD, light therapy is used although the underlying mechanism explaining this success remains unclear. To accelerate the research on defining the light characteristics responsible for inducing a specific effect a uniform manner for specifying the irradiance at the eye should be defined. This allows a genuine comparison between light-affect studies. An important factor impacting the irradiance at the eye are the radiant characteristics of the used light therapy device.

Method: In this study the radiant fluxes of five different light therapy devices were measured. The values were weighted against the spectral sensitivity of the five photopigments present in the human eye. A measurement was taken every five minutes to control for a potential stabilizing effect.

Results: The results show that all five devices show large differences in radiant flux. The devices equipped with blue LED lights have a much lower spectral radiant flux than the devices equipped with a fluorescent light source or a white LED. The devices with fluorescent lamps needed $30 \mathrm{~min}$ to stabilize to a constant radiant flux.

Limitations: In this study only five devices were measured. Radiant flux is just the first step to identify uniform specifications for light therapy devices.

Conclusions: It is recommended to provide all five $\alpha$-opic radiant fluxes. Preferably, the devices should come with a spectral power distribution of the radiant flux. For the devices equipped with a fluorescent lamp it is recommended to provide information on the stabilization time.
\end{abstract}

\section{Introduction}

Light therapy is the treatment of a disorder by exposure to electromagnetic radiation in and close by the visible spectrum (i.e., visible, ultraviolet and infrared radiation). Depending on the type of ailment, treatment is mediated through the skin or through the eyes. This paper only focus on light mediated through the eyes, used in the treatment of Seasonal Affective Disorder (SAD) or circadian related issues like jetlag.

Radiation that is considered from the point of view of its ability to excite the human visual system is called light (CIE, 2011). However, new insights show that light excites not only the human visible system (Image Forming, IF) but as well the non-image forming (NIF) system. The IF system is mediated via the cones and rods enabling respectively photopic and scotopic vision. Activation of the different types of cones (L,M and S-cones) are required for color vision. The NIF system is known for taking cues from the absence or presence of light for example to entrain or adjust the human internal clock to daily (circadian) and seasonal rhythms (Czeisler, 1999; Czeisler et al., 1989; Khalsa et al.,
2003; Spoelstra et al., 2015; St Hilaire et al., 2012). The photosensitive retinal ganglion cells (ipRGC's) are considered to be the main photoreceptors to mediate light to the NIF system, although the cone and rod cells also contribute (Gooley et al., 2010). Light therapy is successfully applied to re-adjust the internal $24 \mathrm{~h}$ clock, e.g. in sleep disorders (van Maanen et al., 2016) or to regulate it, e.g. for jetlags and shift work (Kakooei et al., 2010; Veitch et al., 2003). Moreover, light therapy is successfully applied to treat seasonal affective disorders (SAD; winter depression), other forms of mild depression (Lieverse et al., 2011; Mårtensson et al., 2015; Meesters and Gordijn, 2016), and to enhance cognitive performance or to prevent agitation in patients with dementia (Riemersma-van Der Lek et al., 2008; Sloane et al., 2007; van Hoof et al., 2012).

A guideline on the treatment dose of Seasonal Affective Disorders (Lam and Tam, 2009) suggests that the higher the illuminance, the shorter the necessary exposure time per day: $10.000 \mathrm{~lx}$ for $30 \mathrm{~min}, 5000$ lx for 45-60 min and $2500 \mathrm{~lx}$ for 1-2 hours. When analyzing the literature on light therapy for SAD, positive results for treating SAD were also found out of the suggested dose boundaries. In Fig. 1, the different

\footnotetext{
* Corresponding author.

E-mail address: m.p.j.aarts@tue.nl (M.P.J. Aarts)
} 


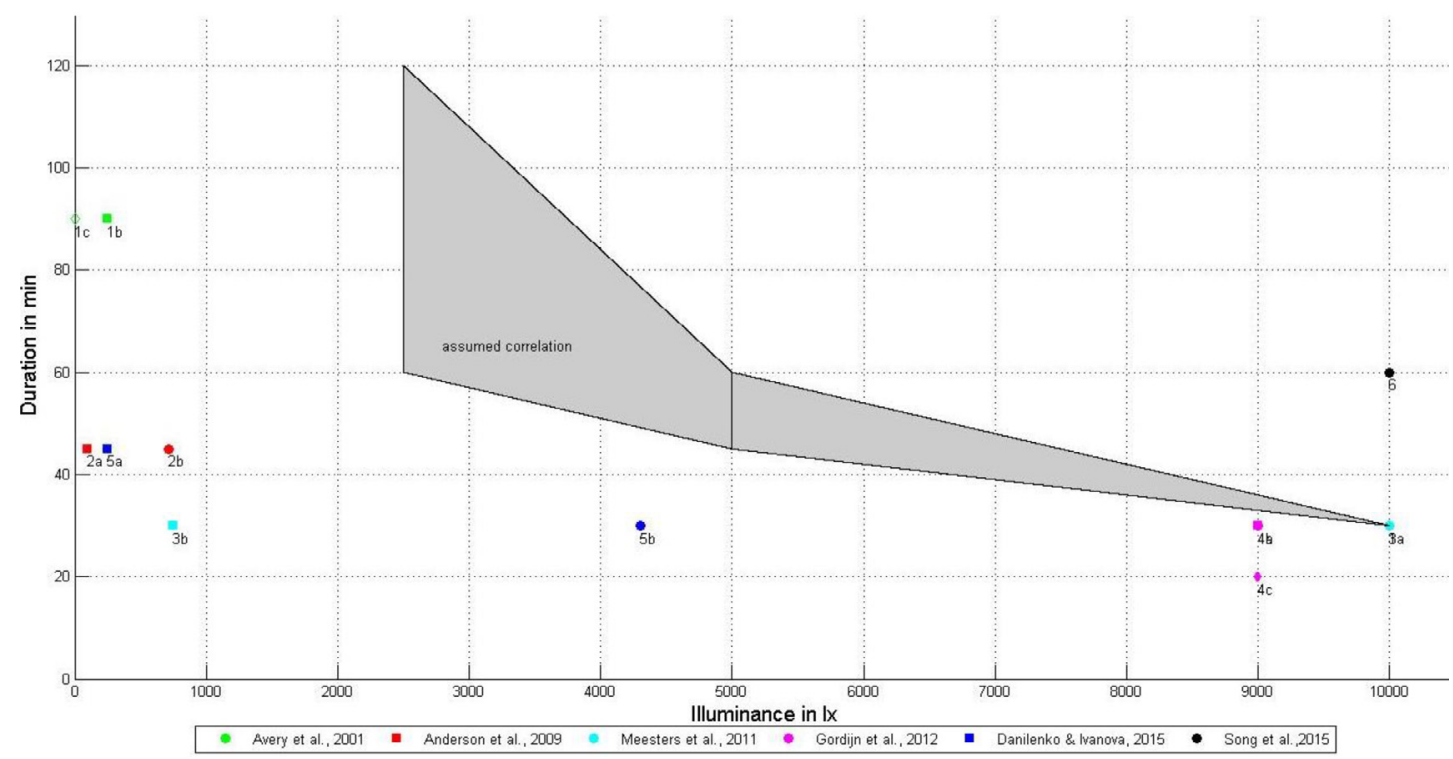

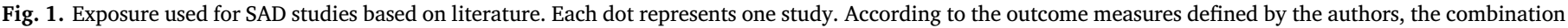

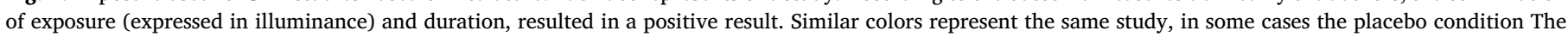
gray area depicts the assumed relationship between the illuminance and the time (Lam and Tam, 2009).

dots represent studies which show positive results (Anderson et al., 2009; Avery et al., 2001; Danilenko and Ivanova, 2015; Gordijn et al., 2012; Meesters et al., 2011; Song et al., 2015). This indicates that the dose for treating SAD is different as earlier suggested. These six studies were included based on the criteria that information should be given about the time and light exposure, more than 10 human subjects over 18 years old without eye problems and other forms of depression participated per intervention, light was the only dependent variable, a standard and comparable diagnose and severity tool was used,. and published after 2000 .

Although light therapy is used as treatment for diverse (affective) disorders, there is currently no consensus in literature on a particular effective radiant exposure (dose depending on the amount, duration and spectral composition) that a light therapy device needs to provide.

In the above mentioned affective studies, the light exposure is described in different quantities, restricting a comparison between these studies. It is therefore essential for bringing Affective Disorder studies with light therapy to the next level, to describe the light exposure of future studies in similar and comparable quantities.

Currently there are numerous ( $>200$ ) different light therapy devices available without medical prescription. The devices vary in characteristics such as size, light source, light output, recommended placement of the device, ultraviolet blocking screens (Baczynska and Price, 2013) and price. Most devices come with some technical specifications while others lack any. Relevant information indicating the purpose of a device for a specific affect is missing in many cases. Some devices lack a user manual while other products indicate the preferred distance between the user (eyes) and the device as well as the recommended duration of a light therapy session. According to the manual of some devices, the viewing direction is not relevant as long as 'the light reaches the eyes'. In general, the specifications and information accompanying the light therapy devices are not standardized, nonuniform, and incomplete.

Considering the above and the technical information provided in different non-comparable quantities it becomes close to impossible for a researcher or a medical practitioner to base a purchase or prescription of a device on an informed decision.

The impact of light therapy from the technical perspective depends on the effective irradiance received by the eyes (energy and spectral composition) in relation to the timing and duration of the exposure
(Lucas et al., 2014).

Since a light therapy device could potentially serve different purposes, the timing and duration of the exposure needs to be based on the aimed effect and consequently also on the individual needs and (ocular) conditions, for example due to the biological ageing of the eye.

As for standard photometry, the illuminance or irradiance at eye level depends on:

1. The radiant characteristics like the radiant flux of the device, the directionality, the luminous surface of the device;

2. The position of the eyes relative to the position of the device;

3. The room characteristics.

When assessing the influence of the eye position relative to the device, one has to consider the direct as well as the indirect radiation (i.e. via multiple reflections) reaching the eye. When light therapy is given in a highly reflective white room, the reflected radiant flux adds significantly to the total irradiance. This is similar for the photometry where the total illuminance is the sum of the direct luminous flux and the reflected luminous flux. In a dark room with low reflective surfaces, the direct component will mainly contribute to the total effective irradiation on a certain position. Therefore the impact of light therapy is dependent on the radiant characteristics of the device, the room characteristics and the position of the device related to the eyes see Fig. 2. Additionally, also the compliance of patients to undergo medical treatment is essential for the impact, and depends on flicker, safety, luminance, colours and its design (Baczynska and Price, 2013).

When considering NIF, it is acknowledged ((Aarts et al., 2017; CIE, 2015a; Lucas et al., 2014) that photometric quantities cannot be used. According to the definition of the International System of Units (SI), "a photobiological or photochemical quantity is defined in purely physical terms as the quantity derived from the corresponding radiant quantity by evaluating the radiation according to its action upon a selective receptor. The quantity is given by the integral over wavelength of the spectral distribution of the radiant quantity weighted by the appropriate actinic action spectrum" (BIPM, 2006). For the visibility the action spectrum is the spectral sensitivity of the human eye for photopic vision, the $V(\lambda)$ curve. With that action spectrum and the maximum of luminous efficacy $\mathrm{K}_{\mathrm{m}}$, one can convert a radiometric quantity $\mathrm{X}_{\mathrm{e}}$ to a photometric quantity $\mathrm{X}$ : 


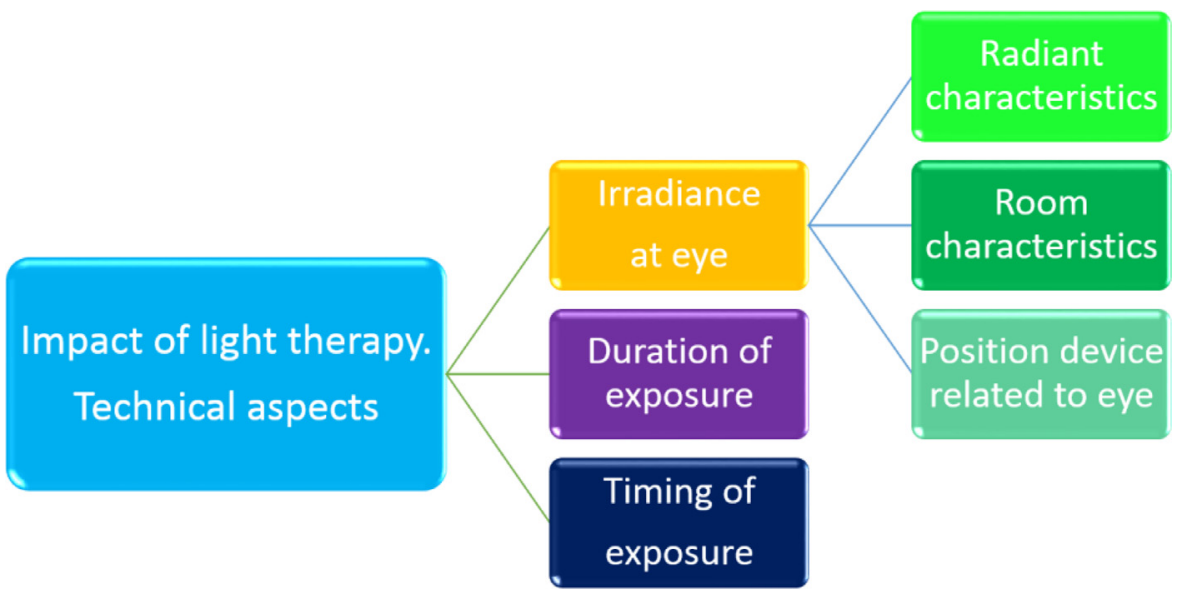

Fig. 2. Different technical aspects impacting the outcome of light therapy.

$X=K_{m} \cdot \int_{\lambda} \frac{\partial X_{e}(\lambda)}{\partial \lambda} \cdot V(\lambda) d$

Instead of referring to the spectral distribution of a quantity via the differential, this is often simplified by referring to this differential using the symbol $X_{e, \lambda}$.

The International Commission on Illumination (Commission Internationale de l'Eclairage, CIE) proposes in their technical note TN002 (CIE, 2014) definitions of new terms relating photochemical quantities to photometric quantities using the same weighing of the radiant quantity with the action spectrum of one of the different effects of light. As an example this technical note gives the blue light hazard weighted radiance, which mathematically is expressed as in Eq. (2):

$L_{B}=\int L_{e, \lambda}(\lambda) \cdot B(\lambda) \cdot d \lambda$

where

$\mathrm{L}_{\mathrm{B}} \quad$ the blue light hazard weighted radiance

$\mathrm{L}_{\mathrm{e}, \lambda} \quad$ the spectral radiance

$\mathrm{B}(\lambda)$ the blue light hazard spectral weighting function

Since the impact of the different photosensitive cells in the eye on NIF effects is not fully comprehended, it has been suggested to use not one action spectrum, like for photometric quantities, but five. The ipRGC are considered to be the dominant photoreceptors of the NIF system. The ipRGC combine their melanopsin based photosensitivity with the photoreception signals of the rods and cones in the ipRGC network (Lucas et al., 2014). In the CIE TN003 (CIE, 2015a) the spectral sensitivity functions are defined, based on the spectral efficiency of the five photopigments detected in the human photoreceptor cells and the spectral transmission properties of the eye:

- Melanopsin is the photopigment of the ipRGC with a peak sensitivity, $\lambda_{\max }$ around $480 \mathrm{~nm}$. Human pre-receptoral filtering (in the standard observer) shifts $\lambda_{\max }$ around $490 \mathrm{~nm}$.

- Rhodopsin is the photopigment of the rod photoreceptors with $\lambda_{\max }$ around $498 \mathrm{~nm}$. Human pre-receptoral filtering shifts $\lambda_{\max }$ around $505-510 \mathrm{~nm}$, the peak for scotopic sensitivity.

- Three cone opsins are the photopigments of the cone photoreceptors; the S-cone opsin cyanolabe with $\lambda_{\max }$ around $420 \mathrm{~nm}$, the M-cone opsin chlorolabe with $\lambda_{\max }$ around $534 \mathrm{~nm}$, and the L-cone opsin erythrolabe with $\lambda_{\max }$ around $564 \mathrm{~nm}$. Human pre-receptoral filtering shifts $\lambda_{\max }$ towards $440 \mathrm{~nm}, 545 \mathrm{~nm}$, and $570-575 \mathrm{~nm}$ respectively.

The CIE proposes the use of five $\alpha$-opic weighted irradiances when describing light in relation to NIF effects, mathematically calculated in the same way as in Eq. (2), weighing the spectral irradiance with the action spectrum of the above mentioned photopigments, see Eq. (3).

$E_{e, a}=\int E_{e, \lambda}(\lambda) \cdot s_{\alpha}(\lambda) \cdot d \lambda$

where

$\mathrm{E}_{\mathrm{e}, \boldsymbol{\alpha}} \quad$ the $\alpha$-opic irradiance

$\mathrm{E}_{\mathrm{e}, \lambda} \quad$ the spectral irradiance

$s_{\alpha}(\lambda) \quad$ the $\alpha$-opic spectral efficiency function

Similar to the description for the $\alpha$-opic irradiance, the $\alpha$-opic radiant flux can be described. With this metric the radiated energy emitted by the device, related to a specific action spectrum can be determined (see Eq. (4)).

$\Phi_{e, \alpha}=\int \Phi_{e, \lambda}(\lambda) \cdot s_{\alpha}(\lambda) \cdot d \lambda$

Where

$\Phi_{\text {e, } \alpha} \quad$ the $\alpha$-opic radiant flux

$\Phi_{\mathrm{e}, \lambda} \quad$ the spectral radiant flux

$s_{\alpha}(\lambda) \quad$ the $\alpha$-opic spectral efficiency function

The aim is to propose uniform specifications for light therapy devices. This will enable researchers studying the effects of light therapy to compare a dose, independent of the device used. Using one set of metrics for describing the (light) exposure characteristics enables the comparison between studies. This will accelerate the research on defining the light characteristic for inducing a specific effect. Introducing a uniform set of specifications for light therapy devices will also help consumers to reach an informed purchase decision.

The study described in this paper focusses on the radiant characteristics of a device.

\section{Method}

When considering the radiant characteristics, a parallel can be drawn between the specifications of luminaires. These specifications provide the relevant information for making a lighting design, aiming to fulfill the visual requirements of the users. These include, among others, the luminous flux ('quantity derived from the radiant flux, $\Phi_{\mathrm{e}}$, by evaluating the radiation according to its action upon the CIE standard photometric observer'(CIE, 2011)). An important difference between visual system and NIF is that instead of photometric quantities, light therapy devices need to provide characteristics based on radiant quantities. In order to indicate the deviation between the devices the five $\alpha$-opic radiant fluxes as proposed by CIE TN003 (CIE, 2015a) will be determined for different light therapy devices. 
Table 1

Specifications of light therapy devices used in this study as provided in the manual. A dash (-) indicates that information was missing.

\begin{tabular}{|c|c|c|c|c|c|}
\hline & Type light source & Light sources & Nominal Irradiance & Illuminance & Dimensions \\
\hline Device A & LED & LED, single peak wavelength $470-475 \mathrm{~nm}$ & $1.5-2.5 \mathrm{~mW} / \mathrm{cm}(46 \mathrm{~cm})$ & $350-400 \mathrm{~lx}$ & - \\
\hline Device $B$ & LED & - & $1.9 \mathrm{~W} / \mathrm{m}^{2}(50 \mathrm{~cm})$ & $220 \mathrm{~lx}(50 \mathrm{~cm})$ & $14.3 \times 14.3 \times 3.5 \mathrm{~cm}^{3}$ \\
\hline Device C & LED & - & $29 \mathrm{~W} / \mathrm{m}^{2}(50 \mathrm{~cm})$ & $2750 \mathrm{~lx}(50 \mathrm{~cm})$ & $29.4 \times 37.6 \times 4.1 \mathrm{~cm}^{3}$ \\
\hline Device $D$ & Fluorescent & $\mathrm{PLL} / 36 \mathrm{~W} / 840$ & - & - & - \\
\hline Device E & Fluorescent & PLL/ 36 W/ 865 & - & $10,000 \mathrm{~lx}$ & - \\
\hline
\end{tabular}

\subsection{Light therapy devices}

The light therapy devices used for this study have been selected based on the following criteria:

1. The manufacturer reported that it effectively treats SAD;

2. Different types of lamps (white LED, blue LED, fluorescent) and therefore different spectral distributions;

3. Freely available for purchase in the country where this study has been performed (the Netherlands).

Based on these criteria five devices have been selected. An overview of the specifications provided in the manual of the device are listed in Table 1.

\subsection{Measurement set-up}

The spectral distribution of radiant flux of each device was measured by using an integrating sphere with a diameter of $3 \mathrm{~m}$. The measurement setup in the integrating sphere can be found in Fig. 3.

The measurements were conducted in the photometric lab according to the guidelines described in LM-79-08 (Iesna, 2008). The spectrometer used for these measurements was the Torus-25-OSF (bandwidth $360-825 \mathrm{~nm}$ ). The raw measurement data was internally post-processed with the Spectrasuite software package. Both, the device and the software, are products from Oceanoptics.

Before starting the actual measurement, the influence of the device itself was determined by performing an absorption measurement. Throughout the absorption measurements, the device was switched off while placed in the center of integrating sphere (position L, Fig. 3), the only light source switched on was the calibrated auxiliary lamp (A). The TORUS spectrometer was placed at point $\mathrm{F}$. The baffles (B) ensured that no direct measurements can be taken at position $\mathrm{F}$. The absorption measurement of each device was directly processed in the result of the actual measurement to correct for the dimensions of the device. For the actual measurement, the device was switched on. A reading was taken every five minutes for a total duration of 30 minutes, the recommended duration of a light therapy session. These five minute interval time series measurements were conducted to check for potential stabilization effects. During the measurements, the air temperature in the sphere was $26^{\circ} \mathrm{C}$ and the relative humidity was $32 \%$.

The spectral radiant flux, was measured with a spectral resolution of less than $1 \mathrm{~nm}$ for a $2^{\circ}$ degree standard observer. The values were converted into the five $\alpha$-opic values, by using the CIE toolbox (CIE, 2015b), a Microsoft Office Excel sheet developed alongside the CIE Technical Note (CIE, 2015a). As the spectral radiant flux was measured for wavelength intervals of less than $1 \mathrm{~nm}$, the measurement data had to be averaged for a $1 \mathrm{~nm}$ range resolution to match the resolution of the $\alpha$-opic action spectra. The toolbox calculated the $\alpha$-opic radiant fluxes in accordance with Eq. (3).

\subsection{Data analyses}

All the measurement data were provided in MS Office Excel-files. The CIE toolbox (CIE, 2015a) to calculate the $\alpha$-opic-related values is a tool developed in MS Office Excel. The data processing is described in paragraph 2.2 Measurement set-up. Post data processing of all data was conducted using MS Excel 2013 and Matlab2013a. The graphs were made in Matlab2013a.

\section{Results}

The spectral distribution of radiant flux of the different light therapy devices is shown in Fig. 4. The two on the top are the light therapy

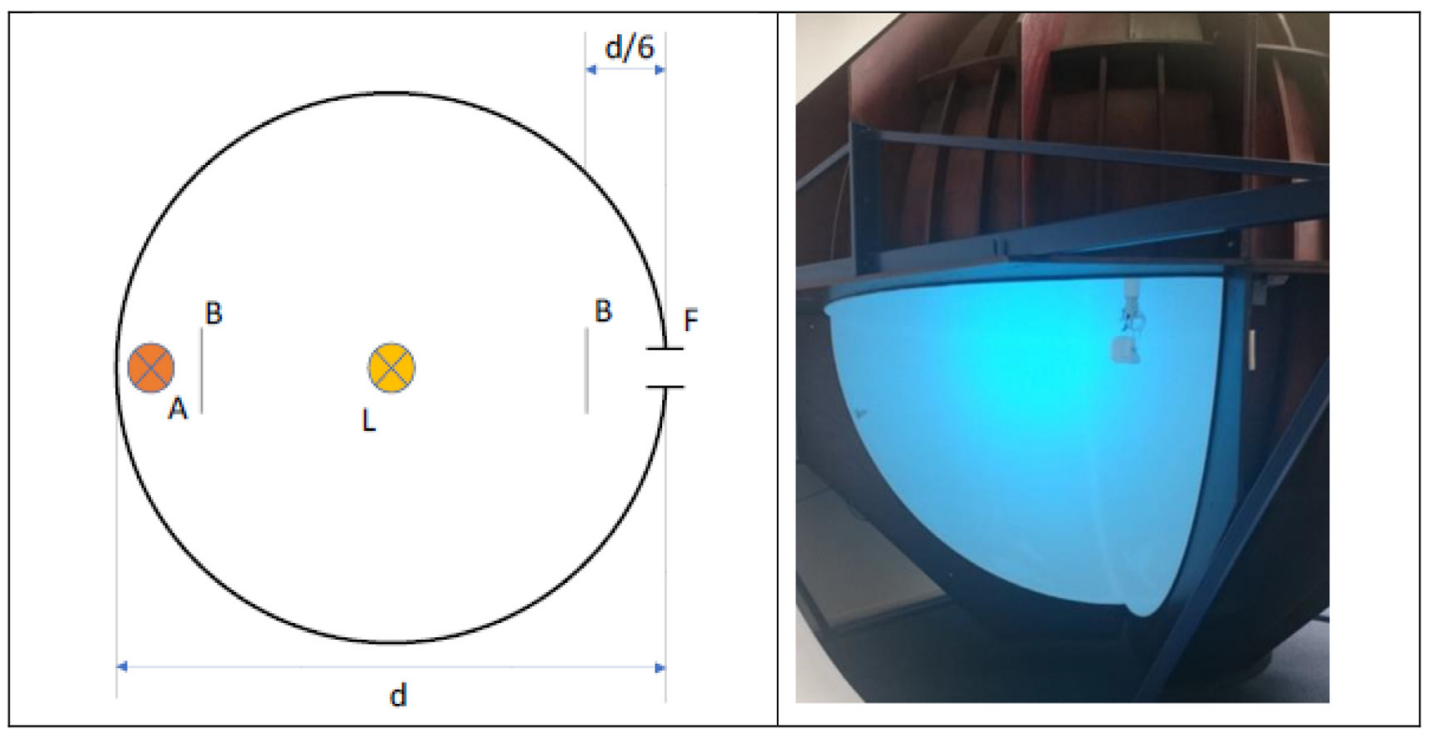

Fig. 3. Left: Measurement setup in an integrating sphere. Right: the integrating sphere used for these measurement. During the measurements the sphere is closed. The device is placed in the center and the picture was taken after the measurements, with the device still turned on. 


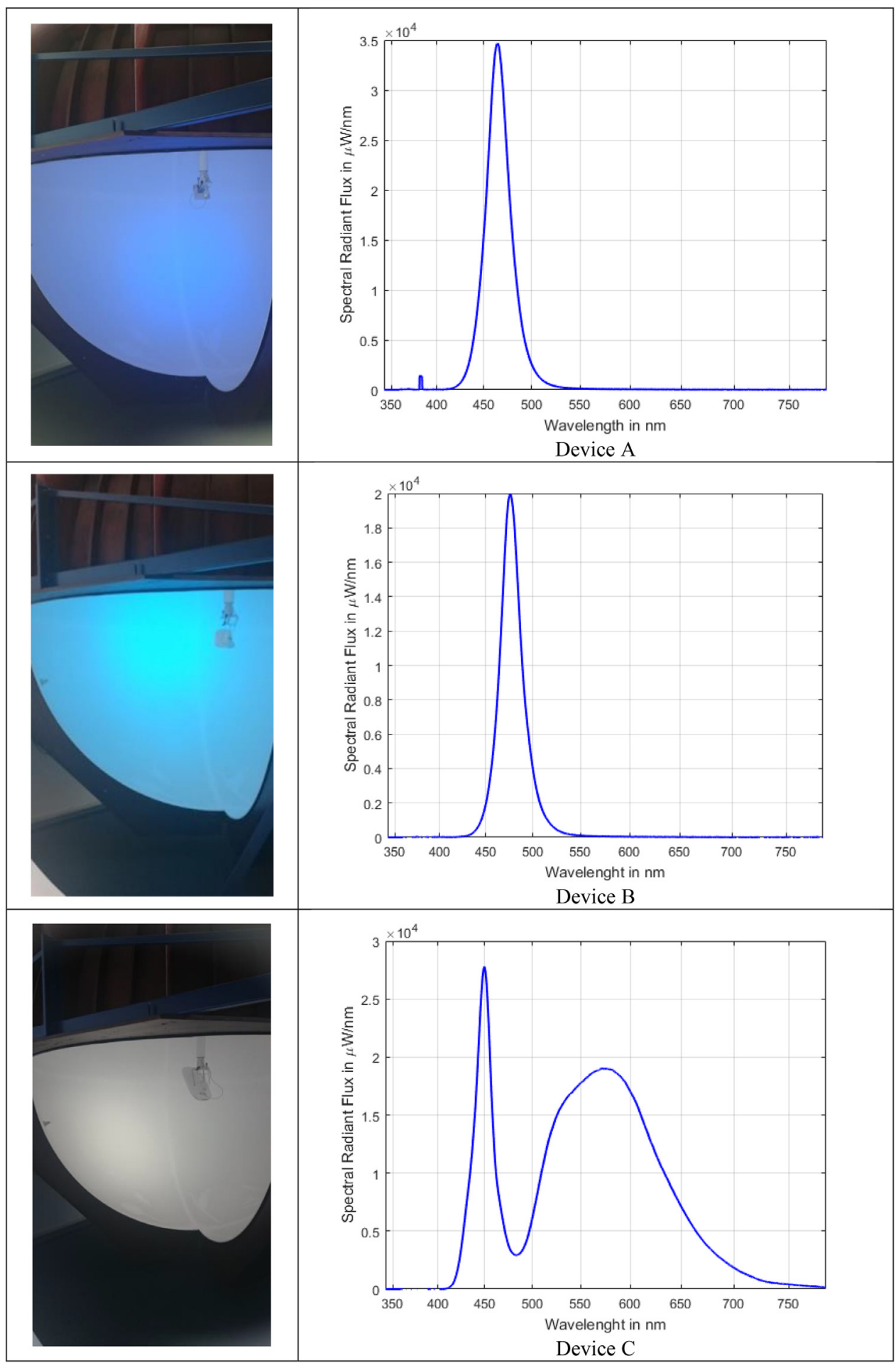

Fig. 4. The spectral power distribution of radiant flux of the devices. Left: a picture of the device in the integrating sphere. Right: the spectral power distribution of the device. Devices D and E were measured every 5 min until stabilization was reached after $30 \mathrm{~min}$.

devices with a blue LED, showing its characteristic monochromatic peak. Device C, equipped with a white LED, shows a smooth curved graph with a peak around $450 \mathrm{~nm}$. The spectral power distribution graphs of Device D and device E show the typical band-with spectrum of a fluorescent lamp. The graphs of both devices show typical peaks at around $450 \mathrm{~nm}$ (Blue), $550 \mathrm{~nm}$ (Green), as well as $600 \mathrm{~nm}$ (Red). The stabilization time is illustrated by the different colored lines based on measurements taken every 5 min until constancy was reached.

Fig. 5 shows the five $\alpha$-opic radiant fluxes for all devices in order to demonstrate the individual differences between the five light therapy devices. Table 2 gives an overview the different radiant fluxes as well as the photometric quantity, luminous flux.

The radiant flux of the three LED devices remained constant over time. The two devices with fluorescent light sources reached stable conditions after $30 \mathrm{~min}$. Table 3 shows the deviation of the melanopic radiant flux over time relative to the stable condition. 


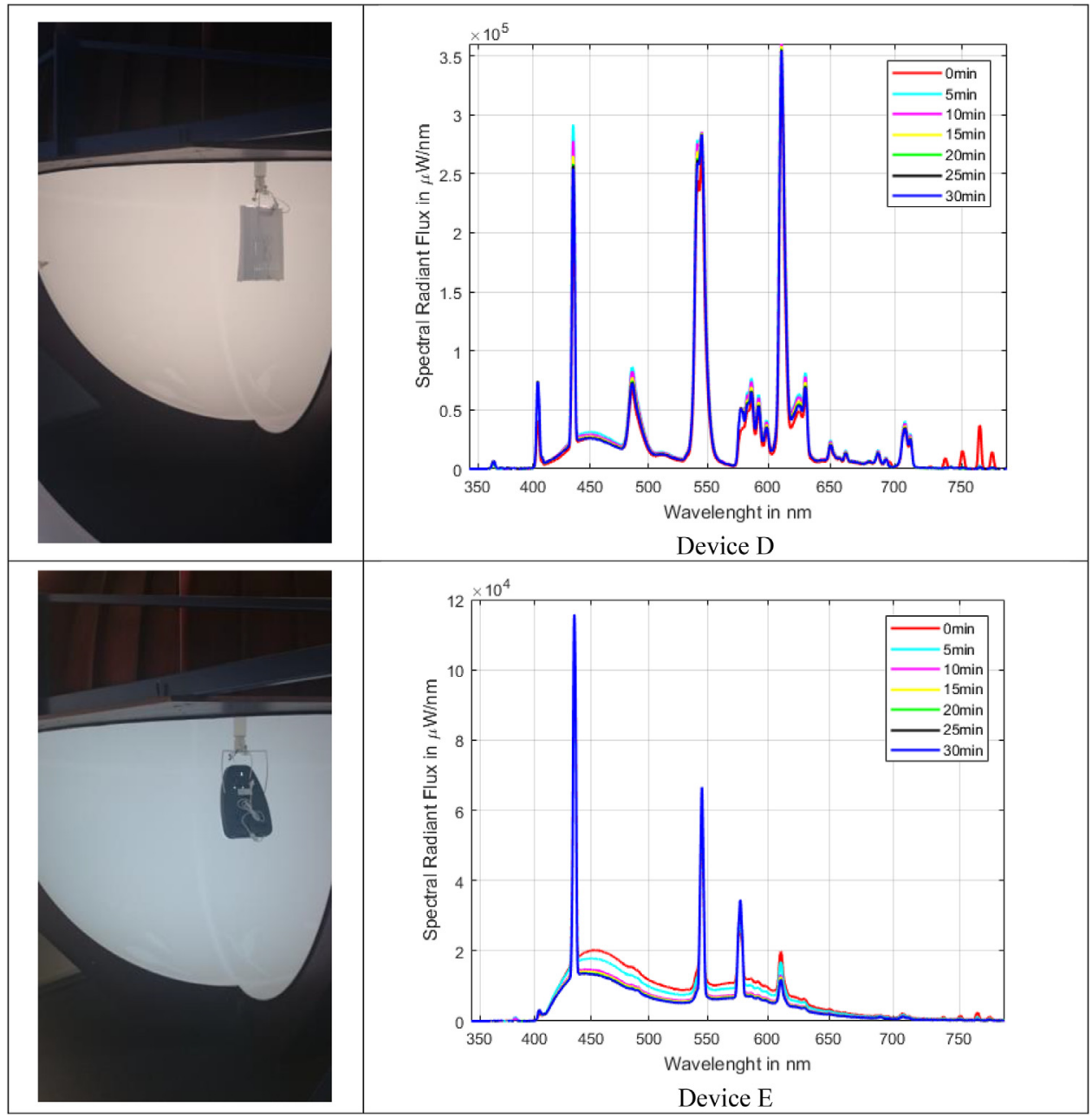

Fig. 4. (continued)

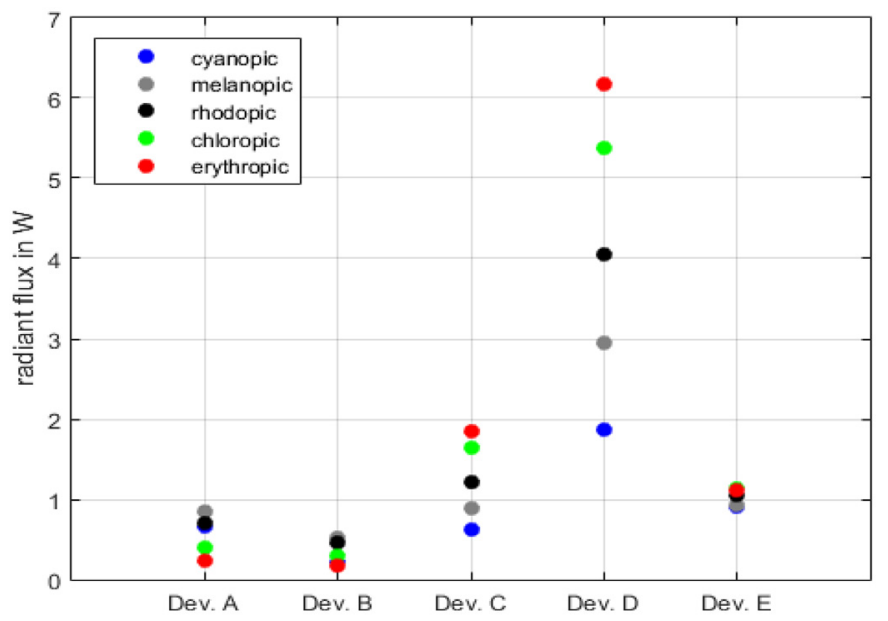

Fig. 5. The five $\alpha$-opic radiant fluxes of the measured light therapy devices.

\section{Discussion}

Table 2 shows the differences in $\alpha$-opic radiant fluxes and luminous fluxes between the five therapy devices. Device A and Device B were developed to trigger a melanopsin response with its peak sensitivity in the bluish part of the spectrum. This explains why the melanopic radiant flux is higher than the other $\alpha$-opic radiant fluxes of both devices. Additionally, expected was that the melanopic radiant flux would be similar for all five devices but the opposite was found; the melanopic flux of Devices A and B where lower than that of Devices C, D and E. The difference of melanopic radiant flux between all five devices is close to a factor six. This is rather large when considering all devices are to generate a similar effect. This also implies that since the dose is higher, the exposure time for the devices with the highest values might be reduced. Since it currently remains unclear which $\alpha$-opic action spectrum contributes to what extent to which affective disorder or other NIF effect, it is recommended to determine all five $\alpha$-opic radiant fluxes of a device. The highest overall values are emitted by Device $\mathrm{D}$ and the lowest by Device B.

The measurements over a period of $30 \mathrm{~min}$ after switching the device on indicate that devices with a fluorescent light source do not have a constant radiation over time. The other, LED-based, devices are and maintain stable after ignition. Both devices $\mathrm{D}$ and $\mathrm{E}$ remain nearly stable after 15 min (Table 3). Device D at ignition gives a lower melanopic radiant flux than the stable value but after 5 min gives a slightly higher output. The clinical relevance of this effect for Device D will probably will minor. For Device E, the radiant exposure at ignition is $48 \%$ higher than after $30 \mathrm{~min}$.

The instable character of Devices D and E are most likely caused by the temperature; the luminous flux of fluorescent light sources depends on the ambient temperature (Pritchard, 1999). The thermal condition inside the device takes a considerable amount of time to reach thermodynamic equilibrium.

The limitation of this study is that only five devices were measured. Radiant flux is the first step to identify uniform specifications for light therapy devices. The next step would be to identify the (weighted) 
Table 2

$\alpha$-opic radiant fluxes of the different light therapy devices.

\begin{tabular}{|c|c|c|c|c|c|c|c|}
\hline Device & $\begin{array}{l}\text { Cyanopic radiant flux } \\
\text { in } W\end{array}$ & $\begin{array}{l}\text { Melanopic radiant flux } \\
\text { in } W\end{array}$ & $\begin{array}{l}\text { Rhodopic radiant flux } \\
\text { in } W\end{array}$ & $\begin{array}{l}\text { Chloropic radiant flux } \\
\text { in } W\end{array}$ & $\begin{array}{l}\text { Erythropic radiant flux } \\
\text { in } W\end{array}$ & $\begin{array}{l}\text { Spectral Radiant flux } \\
\text { in } W\end{array}$ & Luminous flux in $\mathrm{lm}$ \\
\hline$A$ & 0.66 & 0.86 & 0.72 & 0.41 & 0.23 & 1.13 & 80.5 \\
\hline$B$ & 0.22 & 0.53 & 0.46 & 0.29 & 0.17 & 0.60 & 68.7 \\
\hline C & 0.62 & 0.89 & 1.21 & 1.64 & 1.84 & 3.24 & 1116.0 \\
\hline$D$ & 1.85 & 2.93 & 4.03 & 5.37 & 6.19 & 11.15 & 3714.9 \\
\hline$E$ & 0.90 & 0.93 & 1.06 & 1.14 & 1.11 & 2.50 & 656.3 \\
\hline
\end{tabular}

Table 3

The deviation of the melanopic radiant flux from the stable condition over time.

\begin{tabular}{llllllll}
\hline & $0 \mathrm{~min}$ & $5 \mathrm{~min}$ & $10 \mathrm{~min}$ & $15 \mathrm{~min}$ & $20 \mathrm{~min}$ & $25 \mathrm{~min}$ & $30 \mathrm{~min}$ \\
\hline Device D & $-8.5 \%$ & $15.7 \%$ & $11 \%$ & $5.5 \%$ & $1.8 \%$ & $1.2 \%$ & $0 \%$ \\
Device E & $49 \%$ & $30 \%$ & $8 \%$ & $5 \%$ & $1 \%$ & $0 \%$ & $0 \%$ \\
\hline
\end{tabular}

irradiance at the eye.

\section{Conclusion}

For scientific research that aims to identify a relationship between light therapy and an affect, it is clear that merely mentioning the used device is not sufficient.

The results of this study clearly show that the five radiant fluxes of the five tested light therapy devices are not identical. Therefore it is suggested to provide all five $\alpha$-opic radiant fluxes. Preferably, the devices should come with a spectral power distribution of the radiant flux. This enables researchers to determine the radiant flux for any spectral efficiency function, not limited to these five.

Another finding was the impact of thermal stabilization of the devices equipped with fluorescent lamps. Light therapy devices are typically used for treatment purposes during the warm-up period since users may not wait for devices to warm up before starting treatment. Future standards should consider how this is to be addressed when making comparisons between different treatment lamps. The three devices equipped with LED lamps, do not need any stabilization time.

The next procedure in order to enable a comparison of the impact of light therapy devices from a technical perspective, is to define the influence of the room characteristics and the position of the viewer related to the device.

\section{Contributors}

Both authors contributed in the research and in the preparation of this article. The role of the first author was to set-up the study protocol, perform the data analyses and prepare the article. The role of the second author was to give input on the methodology, check the data analyses and prepare the article.

Both authors approved the submitted article.

\section{Role of funding source}

This research did not receive any specific grant from funding agencies in the public, commercial, or not-for-profit sectors.

\section{Statement on additional research data}

You are free to adapt, copy or redistribute the material, providing you attribute appropriately and do not use the material for commercial purposes. Data may only become available when the article is published.

\section{Acknowledgements}

This research did not receive any specific grant from funding agencies in the public, commercial, or not-for-profit sectors. We thank LEDNED for kindly performing the measurements, and Adonia Diakoumis (MSc) for helping with the collection and processing of the data.

\section{References}

Aarts, M.P.J., van Duijnhoven, J., Aries, M.B.C., Rosemann, A.L.P., 2017. Performance of personally worn dosimeters to study non-image forming effects of light: assessment methods. Build. Environ. http://dx.doi.org/10.1016/j.buildenv.2017.03.002.

Anderson, J.L., Glod, C.A., Dai, J., Cao, Y., Lockley, S.W., 2009. Lux vs. wavelength in light treatment of seasonal affective disorder. Acta Psychiatr. Scand. 120, 203-212. http://dx.doi.org/10.1111/j.1600-0447.2009.01345.x.

Avery, D.H., Eder, D.N., Bolte, M.A., Hellekson, C.J., Dunner, D.L., Vitiello, M.V, Prinz, P.N., 2001. Dawn simulation and bright light in the treatment of SAD: a controlled study. Biol. Psychiatry 50, 205-216. http://dx.doi.org/10.1016/S0006-3223(01) 01200-8.

Baczynska, K., Price, L., 2013. Efficacy and ocular safety of bright light therapy lamps. Light. Res. Technol. 45, 40-51. http://dx.doi.org/10.1177/1477153512443062.

BIPM, 2006. The International System of Units (SI), 8th editio. ed.

CIE, 2015a. TN 003:2015 Report on the First International Workshop on Circadian and Neurophysiological Photometry, 2013. Vienna, Austria.

CIE, 2015. CIE TN003 Toolbox [WWW Document]. URL http://files.cie.co.at/784 TN003 Toolbox.xls.. http://files.cie.co.at/784 TN003 Toolbox.xls.

CIE, 2014. CIE TN 002:2014 Relating Photochemical and photobiological quantities to photometric quantities. Vienna, Austria.

CIE, 2011. ILV: International Lighting Vocabulary, CIE S 017/E: 2011. ILV: International Lighting Vocabulary doi:CIE S 017/E.

Czeisler, C.A., 1999. Stability, precision, and near-24-hour period of the human circadian pacemaker. Science 284, 2177-2181. http://dx.doi.org/10.1126/science.284.5423. 2177. (80-.).

Czeisler, C.A., Kronauer, R.E., Allan, J.S., Duffy, J.F., Jewett, M.E., Brown, E.N., Ronda, J.M., 1989. Bright light induction of strong (type 0) resetting of the human circadian pacemaker. Science 244, 1328-1333. http://dx.doi.org/10.1126/science.2734611.

Danilenko, K.V., Ivanova, I.A., 2015. Dawn simulation vs. bright light in seasonal affective disorder: treatment effects and subjective preference. J. Affect. Disorders. http:// dx.doi.org/10.1016/j.jad.2015.03.055.

Gooley, J.J., Rajaratnam, S.M.W., Brainard, G.C., Kronauer, R.E., Czeisler, C.A., Lockley, S.W., 2010. Spectral responses of the human circadian system depend on the irradiance and duration of exposure to light. Sci. Transl. Med.

Gordijn, M.C.M., 't Mannetje, D., Meesters, Y., 2012. The effects of blue-enriched light treatment compared to standard light treatment in seasonal affective disorder. J. Affect. Disord. 136, 72-80. http://dx.doi.org/10.1016/j.jad.2011.08.016.

Iesna, 2008. IES approved method: electrical and photometric measurements of solidstate lighting products. IES LM-79-80 In: IES Subcomm. Solid-State Light. IES Test. Proced. Comm. doi:ISBN 978-0-87995-226-6.

Kakooei, H., Ardakani, Z.Z., Ayattollahi, M.T., Karimian, M., Saraji, G.N., Owji, A.A., 2010. The effect of bright light on physiological circadian rhythms and subjective alertness of shift work nurses in Iran. Int. J. Occup. Saf. Ergon. 16, 477-485. http:// dx.doi.org/10.1080/10803548.2010.11076860.

Khalsa, S.B.S., Jewett, M.E., Cajochen, C., Czeisler, C.A., 2003. A phase response curve to single bright light pulses in human subjects. J. Physiol. 549, 945-952. http://dx. doi. org/10.1113/jphysiol.2003.040477.

Lam, R.W., Tam, E.M., 2009. "A clinician's guide to using light therapy. Clin. Res. Package.

Lieverse, R., Van Someren, E.J.W., Nielen, M.M.A., Uitdehaag, B.M.J., Smit, J.H., Hoogendijk, W.J.G., 2011. Bright light treatment in elderly patients with nonseasonal major depressive disorder: a randomized placebo-controlled trial. Trails.

Lucas, R.J., Peirson, S.N., Berson, D.M., Brown, T.M., Cooper, H.M., Czeisler, C.A., Figueiro, M.G., Gamlin, P.D., Lockley, S.W., O'Hagan, J.B., Price, L.L.A., Provencio, I., Skene, D.J., Brainard, G.C., 2014. Measuring and using light in the melanopsin age. Trends Neurosci.

Mårtensson, B., Pettersson, A., Berglund, L., Ekselius, L., 2015. Bright white light therapy in depression: a critical review of the evidence. J. Affect. Disord. 182, 1-7. http://dx. doi.org/10.1016/j.jad.2015.04.013.

Meesters, Y., Dekker, V., Schlangen, L.J.M., Bos, E.H., Ruiter, M.J., 2011. Low-intensity 
blue-enriched white ligth $(750 \mathrm{~lx})$ and standard brigth light $(10000 \mathrm{~lx})$ are equally effective in treating SAD. A randomized controlled study. BMC Psychiatry 11, 17. http://dx.doi.org/10.1186/1471-244X-11-17.

Meesters, Y., Gordijn, M.C.M., 2016. Seasonal affective disorder, winter type: current insights and treatment options. Psychol. Res. Behav. Manag. 9, 317-327. http://dx. doi.org/10.2147/PRBM.S114906.

Pritchard, D.C., 1999. Lighting, 6th ed. Pearson Education Limited, Harlow.

Riemersma-van Der Lek, R.F., Swaab, D.F., Twisk, J., Hol, E.M., Hoogendijk, W.J.G., Van Someren, E.J.W., 2008. Effect of bright light and melatonin on cognitive and noncognitive function in elderly residents of group care facilities: a randomized controlled trial. JAMA-J. Am. Med. Assoc.

Sloane, P.D., Williams, C.S., Mitchell, C.M., Preisser, J.S., Wood, W., Barrick, A.L., Hickman, S.E., Gill, K.S., Connell, B.R., Edinger, J., Zimmerman, S., 2007. High-intensity environmental light in dementia: effect on sleep and activity. J. Am. Geriatr Soc.

Song, C., Luchtman, D., Kang, Z., Tam, E.M., Yatham, L.N., Su, K.-P., Lam, R.W., 2015 Enhanced inflammatory and T-helper-1 type responses but suppressed lymphocyte proliferation in patients with seasonal affective disorder and treated by light therapy. J. Affect. Disord. 185, 90-96. http://dx.doi.org/10.1016/j.jad.2015.06.003.

Spoelstra, K., van Grunsven, R.H.A., Donners, M., Gienapp, P., Huigens, M.E., Slaterus, R., Berendse, F., Visser, M.E., Veenendaal, E., 2015. Experimental illumination of natural habitat-an experimental set-up to assess the direct and indirect ecological consequences of artificial light of different spectral composition. Philos. Trans. R. Soc. Lond. B Biol. Sci. 370.

St Hilaire, M.A., Gooley, J.J., Khalsa, S.B.S., Kronauer, R.E., Czeisler, C.A., Lockley, S.W., 2012. Human phase response curve to a $1 \mathrm{~h}$ pulse of bright white light. J. Physiol. 590, 3035-3045. http://dx.doi.org/10.1113/jphysiol.2012.227892.

van Hoof, J., Westerlaken, A.C., Aarts, M.P.J., Wouters, E.J.M., Schoutens, A.M.C., Sinoo, M.M., Aries, M.B.C., 2012. Light therapy: methodological issues from an engineering perspective. Technol. Heal. Care.

van Maanen, A., Meijer, A.M., van der Heijden, K.B., Oort, F.J., 2016. The effects of light therapy on sleep problems: a systematic review and meta-analysis. Sleep Med. Rev.

Veitch, J.A., Beld, G. van den, Brainard, G.C., Roberts, J.E., 2003. Ocular Lighting Effects on Human Physiology, Mood and Behaviour 61. 